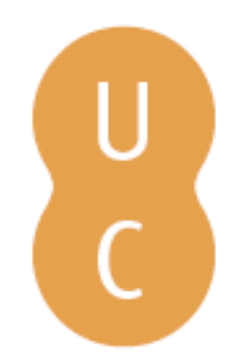

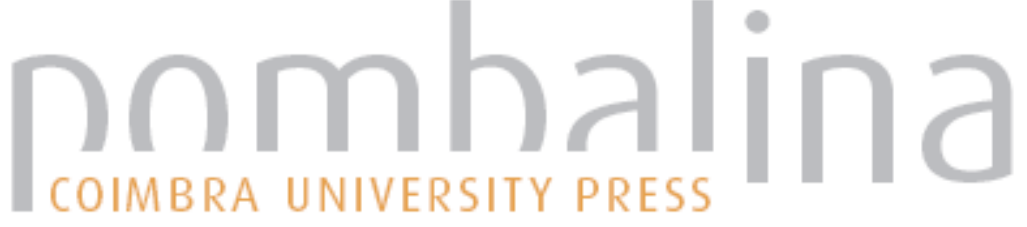

\section{Figurações de São Paulo nas Vidas e Paixões dos Apóstolos}

\author{
Autor(es): $\quad$ Machado, Ana Maria \\ Publicado por: Imprensa da Universidade de Coimbra \\ URL \\ persistente: $\quad$ URI:http://hdl.handle.net/10316.2/38679 \\ DOI: $\quad$ DOI:http://dx.doi.org/10.14195/978-989-26-1164-8_2
}

Accessed : $\quad$ 26-Apr-2023 16:05:11

A navegação consulta e descarregamento dos títulos inseridos nas Bibliotecas Digitais UC Digitalis, UC Pombalina e UC Impactum, pressupõem a aceitação plena e sem reservas dos Termos e Condições de Uso destas Bibliotecas Digitais, disponíveis em https://digitalis.uc.pt/pt-pt/termos.

Conforme exposto nos referidos Termos e Condições de Uso, o descarregamento de títulos de acesso restrito requer uma licença válida de autorização devendo o utilizador aceder ao(s) documento(s) a partir de um endereço de IP da instituição detentora da supramencionada licença.

Ao utilizador é apenas permitido o descarregamento para uso pessoal, pelo que o emprego do(s) título(s) descarregado(s) para outro fim, designadamente comercial, carece de autorização do respetivo autor ou editor da obra.

Na medida em que todas as obras da UC Digitalis se encontram protegidas pelo Código do Direito de Autor e Direitos Conexos e demais legislação aplicável, toda a cópia, parcial ou total, deste documento, nos casos em que é legalmente admitida, deverá conter ou fazer-se acompanhar por este aviso.

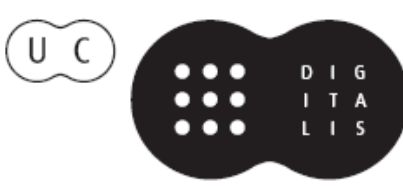


Ana Maria Machado

Universidade de Coimbra / Centro de Literatura Portuguesa

\section{FIGURAÇÕES DE SÃo PAULO NAS VIDAS E PAIXÕES DOS APÓSTOLOS}

Apóstolo, pregador, teólogo, figura instigante de um tempo ostensivamente conflitivo, Paulo desencadeou hostilidades e paixões decisivas na vivência e no pensamento religiosos dos primórdios da era de Cristo e nos textos que desde cedo pulverizaram a sua imagem. A controvérsia que envolve este fundador do Cristianismo, explicável por motivos históricos, nem todos cabalmente esclarecidos, complexifica-se com a discussão em torno de cartas autênticas, apócrifas, interpolações posteriores, narrativas neutralizadoras de conflitos entretanto ultrapassados ou, no mínimo, vividos com distintos contornos. Deste emaranhado, prevalece no senso comum a imagem da conversão súbita e radical, na esteira do relato dos Atos dos apóstolos e do modo como estes romancearam as experiências pessoais evocadas nas epístolas.

Ora as comemorações do Ano Paulino, entre 2008 e $2009^{2}$, vieram justamente renovar a reflexão crítica sobre a figura do apóstolo de Tarso e a aparente evidência de algumas propostas, a contrariar o conhecimento tradicional acerca do santo, estimulou a releitura tanto dos textos bíblicos quanto o repensar das imagens que a partir deles se forjaram ao longo dos tempos. Assim, guiada por insistentes chamadas de atenção tanto para a primazia das cartas paulinas

\footnotetext{
1 Uma versão reduzida deste trabalho foi apresentada ao XIII Congreso Internacional de la Asociación Hispánica de Literatura Medieval, Valladolid, Setembro de 2009.

2 "Foi a 28 de junho de 2007 que Bento XVI anunciou a celebração de um ano jubilar dedicado ao Apóstolo São Paulo: "É para mim uma felicidade anunciar oficialmente que ao Apóstolo Paulo dedicaremos um especial Ano jubilar, desde 28 de junho de 2008 até 29 de junho de 2009, por ocasião do bimilenário do seu nascimento, inserido pelos historiadores entre os anos 7 e 10 d.C.»". http://www.ecclesia.pt/anopaulino/. Consultado em janeiro de 2009.
} 
autênticas, determinantes para uma aproximação à primeira geração cristã, como para a necessidade de entender a intenção conciliadora do autor dos Atos dos apóstolos e a sua ligação a um tempo posterior de judaísmo palestiniano ortodoxo, de matriz farisaica (Neves, 2011), pareceu-me interessante revisitar as representações literárias de Paulo nas narrativas hagiográficas portuguesas que a Idade Média conservou e tentar perceber não apenas que traços deste pilar do Cristianismo foram valorizados e/ou negligenciados, mas também a posição dos autores / compiladores / tradutores em relação ao retratado.

Do corpus a selecionar constam os capítulos dedicados a Paulo em Vidas e paixões dos apóstolos (século xIv), tradução portuguesa do segundo volume da compilação hagiográfica que Afonso X encomendara ao seu colaborador Bernardo Brihuega (último quartel do século xiII) ${ }^{3}$, e no Flos sanctorum de 1513, tradução portuguesa da Legenda aurea (1360-1390), do dominicano Tiago de Varazze concretamente, nos capítulos Conversão de São Paulo e Vida de São Paulo. Neste trabalho ocupar-me-ei apenas da primeira compilação, ficando os textos do Flos sanctorum para ulterior desenvolvimento.

Nos dois legendários confirma-se a quase constante associação medieval entre Pedro e Paulo que se encontra tanto na liturgia como nas festas eclesiásticas, embora, globalmente, o apóstolo convertido tenha sido ofuscado devido à dignidade hierárquica alcançada pelo primeiro papa. Em termos de obra, pelo contrário, as epístolas de Paulo foram as mais lidas: as cartas aos Gálatas e aos Romanos, no Ocidente, e as endereçadas aos Coríntios, entre gregos e bizantinos (Vauchez, 2001).

Tal como ocorre com outras figuras bíblicas, também as lacunas na biografia de Paulo suscitaram um conjunto importante de textos apócrifos que inspiraram

3 Este seria o segundo dos cinco livros da Genesi Alfonsii, dedicada à história do Cristianismo (Jesus e Santa Maria, Mártires, Confessores e Virgens). Do original castelhano, hoje perdido, subsistem em português os livros II e III (Vida e Paixão dos Mártires). Das Vidas e Paixões dos Apóstolos, a Biblioteca Nacional apenas conserva duas cópias da tradução portuguesa, feita provavelmente na corte de D. Dinis: uma do século xv (1442-1443), no cód. alc. CCLXXXII/280, e um fragmento do século xIV, no MS. 5, n. 28. A pedido de D. Leonor, foi feita uma impressão em Lisboa, por Valentim Fernandes, em 1505, com o título Autos dos Apostolos (Cepeda, 1975; Cepeda, 1982-1989; Cepeda, 1993; Martins, 1949; Martins, 1963).

4 No espaço nacional preservaram-se quatro cópias latinas que remontam aos séculos xiI a Xv. Das traduções portuguesas conservaram-se um fragmento do século xv, entretanto desaparecido (Viegas, 1916) e Ho Flos sanctorum em lingoagẽ português (impresso em Lisboa, em 1513, por Hermão de Campos e Roberto Rabelo). 
parte substancial da hagiografia paulina medieval. Refiro-me sobretudo aos Acta Pauli (190-200), para o Flos sanctorum, e à Passio sanctorum apostolorum Petri et Pauli (século Iv), para as Vidas e paixões dos apóstolos. Aquelas obras, excluídas do cânone pelo decreto Pseudo-Gelasiano (século vi), foram perfeitamente integráveis em refundições hagiográficas como as de Bernardo de Brihuega ou na Legenda aurea, de Tiago de Varazze.

Se, sobretudo nas Vidas e paixões dos apóstolos, a imagem que nos é legada não pode distar muito da que foi construída pelos Atos dos apóstolos, na Legenda aurea, a possibilidade de disseminação de vidas é bem maior, na medida em que, por força do par Pedro e Paulo e das conexões com outros discípulos, este último é abordado em vários capítulos, sem que tenha havido a preocupação de forjar uma coerência entre as fontes usadas e o seu aproveitamento. De todo o modo, ambos os retratos estão, tal como ainda hoje, marcados pela imagem apresentada nos Atos dos apóstolos, e só muito pontualmente se abrem à informação e à personalidade que as cartas revelam. Assim, nas traduções portuguesas insiste-se na imagem do convertido, do apóstolo cujo estatuto se discute, da itinerância pastoral incansável num espaço alargado que vai da Ásia Menor a Roma, dos conflitos, perseguições e agressões que suscita, culminando no seu martírio às mãos de Nero. A controvérsia doutrinal é evidente nas Vidas e paixões dos apóstolos e, por muito que se tente neutralizar ou atenuar, é visível que o universalismo da pregação de Paulo, opondo a graça à lei mosaica e afirmando a novidade da ressurreição e a parusia, incomodou sobremaneira judeus e pagãos e, na crítica do ritualismo, os apóstolos judaizantes. Esta tensão, percetível nos textos bíblicos, aflora igualmente nas hagiografias medievais em pauta, sem que, num e noutro caso, seja possível dilucidar os exatos contornos sociológicos, religiosos e teológicos do problema.

Ainda que, nas suas redações originais, os dois macrotextos a considerar remontem a finais do século xıII, optei por privilegiar a representação de Paulo nas Vidas de Bernardo de Brihuega, não só porque a tradução portuguesa precede a tradução do legendário dominicano, mas porque, sendo aquela mais abrangente em termos biográficos, ajudará a clarificar o sentido das opções que o Flos sanctorum ecoa.

Como se sabe, os Atos dos apóstolos narram a ação evangélica e apostólica de Pedro e Paulo, os dois pilares maiores do Cristianismo. A falta de diálogo 
com as epístolas paulinas, primeiros testemunhos da experiência cristã, gerou naturais contradições entre o relato pessoal e o reportado, forjou uma identidade paulina mais consensual, numa narrativa propensa a diluir fissuras que se esboçavam sobretudo em torno da Igreja de Jerusalém e de Antioquia. Porém, a receção medieval dos Atos, no seu projeto refundidor, surpreende o leitor pelas interferências com repercussão na imagem do autor e do santo - esboços de leitura crítica, esclarecimentos legitimadores das dissensões entre os apóstolos, acrescentos de pertinência desigual. Tal como o autor dos Atos em relação à conversão do apóstolo, também Bernardo de Brihuega quis colmatar hiatos, o maior dos quais diz respeito à morte de Paulo em Roma, uma vez que a narrativa dos Atos termina nos seus dois primeiros anos na cidade (28, 30-31), abrindo espaço, como se verá, a toda a sorte de fantasias.

De facto, não se tratando de uma biografia dos apóstolos, as Vidas contêm a informação mais completa sobre os feitos de São Paulo, tendo o complilador a preocupação de indicar as fontes seguidas, quando, abandonando Lucas - o autor então incontestado dos Atos dos apóstolos ${ }^{5}$ - recorre às cartas do apóstolo, geralmente aos Gálatas, através da Glosa ordinária, ou à Passio sanctorum apostolorum Petri et Pauli, do Pseudo-Marcelo, ou, mais pontualmente, a Beda, à História escolástica, entre outros, ou ainda à sua própria opinião ou de autores não identificados. Em matéria tão delicada como a das seitas religiosas, a multiplicação de vozes compromete a coerência textual ${ }^{6}$, embora, nalguns casos, prolongue a propensão dos Atos para o romanesco hagiográfico, alimentando o gosto pelo maravilhoso, multiplicando as aventuras e os combates doutrinais, sempre com vista à glorificação dos apóstolos. Mesmo assim, é com surpresa que verificamos como, estribado noutros autores, Bernardo de Brihuega não hesita em questionar a informação lida no Atos dos apóstolos, confrontando-a com a mais fiável que lê (ou que as suas fontes leram) nas cartas.

Do ponto de vista narrativo, as Vidas e paixões dos apóstolos adotam a sequência dos Atos, a saber, o passado de Paulo enquanto perseguidor de cristãos, a conversão, a evangelização itinerante e as reações favoráveis e adversas à sua

5 Não o companheiro de Paulo em algum das suas viagens. A crítica recente tem discutido se, em 90-100, viveria o Lucas histórico, autor do Evangelho e dos Atos (Neves, 2008).

6 Veja-se, por exemplo, como o apelo para César, motivo da viagem de Paulo a Roma, é completamente negligenciado nas Vidas e Paixões dos Apóstolos e se dilui no conflito com Simão Mago. 
pregação, com as consequentes conversões, milagres, mas também perseguições, agressões e prisões, o regresso a Jerusalém, as divergências no entendimento da relação entre a lei mosaica e a graça de Cristo e a condenação que conduz o apóstolo a Roma. Contudo, dado que os Atos apenas referem os seus dois primeiros anos na capital do Império, no final, Bernardo de Brihuega acrescenta o relato da morte de Paulo recorrendo à Passio Petri et Pauli. Neste quadro, São Paulo é representado essencialmente na sua incessante itinerância em prol do evangelho de Cristo e na fortaleza com que aceita e enfrenta todas as ameaças.

$\mathrm{Na}$ conformação da personagem, o compilador respeita a atenção ao passado de Paulo, desde o tempo de perseguidor dos cristãos, passando pela conversão miraculosa e culminando na pregação doutrinal subsequente. Ao enfatizar o antagonismo entre os dois polos do seu percurso, erige Paulo em paradigma de um dos temas mais insistentemente discutidos: o trânsito do Judaísmo para o Cristianismo ou, melhor dizendo, para o judeo-cristianismo que caraterizou as primeiras gerações. Neste contexto, são frequentes as dissensões entre os judeus da Torah e os da "carreira de Nosso Senhor", ou seja, daqueles que em Antioquia são pela primeira vez designados cristãos, seguindo, de acordo com a explicação retirada de Pedro Comestor, o costume das escolas filosóficas ${ }^{7}$, mas também abundam as disputas sobre a relação de Paulo ou dos judeus com os pagãos.

A reescrita dos Atos revela um autor atento quer ao seu hipotexto, quer à leitura dos comentaristas. A modalidade questionadora e amplificadora, embora diminua à medida em que a narração dos feitos de Paulo avança ${ }^{8}$, manifesta-se a propósito da morte de Estêvão, ou seja, ainda antes de Paulo entrar em cena?. Tanto os Atos (7, 54-60) como as Vidas e paixões dos apóstolos (I, c. 14, 67-84) atestam que "as testemuinhas poseram sas vesteduras a par dos pees de ũu

\footnotetext{
7 "os gentios de Antioquia poserom-lhes nome cristãos, do nome de Cristo, o seu meestre, assi como em nas seitas dos filosofos que todos eram chamados dos nomes de seus mestres". Cf. I, c. 28, 138. Identifico a citação apenas com indicação de volume, capítulo e página.

8 Em consequência da dimensão física que a obra está a adquirir, a partir do 77. capítulo, o autor obriga-se a refrear as citações (Cepeda, 1982).

9 A Vida e paixão dos apóstolos segue o plano de Act 8,2, com a diferença de explicitar o plano naquele jeito muito medieval que António José Saraiva, a propósito de Fernão Lopes, designou "placas giratórias", ou seja, processos de transportar o leitor de um espaço ou acção para um outro: "E, por ende, vos leixaremos aqui agora de falar del e dos outros discípulos que andavam esparjudos pregando per terra de Judea e de Samaria, e de Saulo, o mancebo que vos dissemos que foi depois Sam Paulo, que os andava correndo, e contar-vos-emos dos apóstolos, que ficarom em Jerusalem, em como fezerom Santiago, o meor, o filho de Alfeu, bispo de Jerusalem" (I, c. 14, 84). Identifico a citação apenas com indicação de volume, capítulo e página.
} 
mancebo que havia nome Saulo. E apedravam Sancto Stevam (...) E Saulo consentio em sa morte" (I, c. 14, 80-81). A conivência com o martírio do santo deverá ter suscitado enormes perplexidades, dada a presumível inconciliabilidade com a identidade do futuro apóstolo, pregador e santo. Por consequência, no final do capítulo, Bernardo de Brihuega corrige a putativa dissonância, e, talvez movido por Beda a quem, de seguida, explicitamente recorre, esclarece em que consistira este consentimento, desfazendo quaisquer suspeitas de envolvimento físico que pudessem macular a imagem do santo:

E, sobre o que disse (...), sabede vós que aquel Saulo foi Sam Paulo, o apostolo que coverteo depois Nostro Senhor, assi como adeante ouviredes. E, porque o queria por seu apostolo e por seu pregador, por ende o gardou que nunca tirou pedra contra Sancto Stevam nem luxou sas mãos em sangue de nem ũu sancto. (I, c. 14, 83)

E, na esteira do monge Venerável, prepara a exemplaridade da conversão, alertando para o castigo que de outro modo o esperaria: "Mais diz Beda que, porque o nom apedrou, consentio com os que o apedravam. E por ende perecera tam bem come eles se nom o ajudasse a graça de Deus e o rependimento que houve" (ibid.).

Já na emenda do itinerário que Lucas atribui a Paulo, após a conversão, Bernardo de Brihuega intervém mas, sem aduzir a informação de Act 9, 26-29, substitui-a pelo testemunho do próprio apóstolo na epístola aos Gálatas (1:17):

E, segundo como conta el mesmo Sam Paulo em na Pístola que enviou depois aos de Galas, nom foi ele aos de Jerusalem logo tanto que foi convertido, ante se foi pera Arabia e andou per i pregando três anos mui fortemente per todolos logares. E, a cabo dos três anos, tornou-se pera Damasco. (I, 22, 116)

Depois da discussão sobre a data da conversão (I, 22, 116-117), a partir da Estoria escolastica, o autor regressa aos Atos (9, 23) ${ }^{10}$ acrescentando uma motivação que só remotamente daí poderia ser inferida, mas que de facto surge no

10 Cf. I, c. 22, 117: "depos muitos dias quiserom os judeos de Damasco matar Sam Paulo". 
versículo seguinte da carta ${ }^{11}$ e é mais vagamente referida em Act 9, 26². Na continuação, Bernardo de Brihuega recorre a Beda, que tenta conciliar a carta com os Atos, transferindo o momento da ameaça dos inimigos para a ida de Paulo para Jerusalém, de facto uma consequência da perseguição que lhe moviam:

Mais sabede que, logo depos aquesto, conta San Lucas em este capitolo como depos muitos dias quiserom os judeus de Damasco matar Sam Paulo e de como foi ele a Jerusalem por ver Sam Pedro. Mais, porque diz Beda que em aquelas palavras que põe Sam Lucas dizendo que "depos muitos dias", se mostra que lhe nom aconteceo aquesto em na primeira viinda que el fez a Damasco quando foi i convertido, mais em na segunda. (I, c. 22, 117) ${ }^{13}$

O compilador medieval reorganiza o itinerário de Paulo, de acordo com o testemunho do apóstolo e a interpretação de Beda, e só quando, no capítulo $27^{14}$, retoma a pregação da Arábia (132) e o regresso a Damasco (133), enxerta de novo a correção no ponto onde havia suspendido a narração de Paulo (Act 9, 23). Tempo, itinerário e motivação clarificam-se no final do capítulo, quando se cita um trecho da carta aos Gálatas. Embora repetições e correções não tenham contribuído para a evidência do percurso, neste momento Bernardo de Brihuega cita em latim e traduz o relato de Paulo que antes fragmentariamente reportara, assentando a versão definitiva sobre a matéria:

Mais, quando prougue aaquel que me apartou do ventre de minha madre e me chamou pela sua graça por descobrir em mi o seu Filho e que o pregasse aas gentes, non andei eu logo a sabor da carne nem do sangue nem vĩi a Jerusalem a meus antecessores, os apóstolos, mais fui-me pera Arabia e tornei-me outra vez

11 Cf. Gal 1,18: "deinde post annos tres veni Hierosolyma videre Petrum et mansi apud eum diebus quindecim”. Sublinhado meu.

12 Cf. Act 9, 26: "cum autem venisset in Hierusalem temptabat iungere se discipulis et omnes timebant eum non credentes quia esset discipulus".

13 Segue-se a repetição de Gal 1:17, prolongando-a com o versículo seguinte onde, de facto, se lê que, passado três anos, Paulo foi a Jerusalém para visitar Pedro $(1,18)$. Sublinhado meu.

14 No final do capítulo 22, Bernardo de Brihuega mudara de novo de protagonista: "por ende vos leixaremos nós aqui agora de falar daquesto e tornar-vos-emos a contar do que aconteceo a Sam Pedro enquanto Sam Paulo andou per terra de Arabia pregando" (I, 117). 
pera Damasco. E, depois de três anos, vĩi-me pera Jerusalem pera veer Sam Pedro. (I, c. 27, 135)

Estribado num aparente confronto com as cartas - segundo alega, a partir da "Pistolia que enviou aos de Galas" (133) ${ }^{15}$, de facto, 2 Cor 32 e, ao que tudo indica, seguindo a Glossa ordinaria ${ }^{16}$-, Bernardo de Brihuega procedera a uma outra correção: a responsabilidade das ameaças à vida de Paulo pendem agora não sobre os judeus, como consta em Atos (9, 23-24), mas sobre "os cidadãos da vila com o adeantado do seu rei que havia nome Areta, ca se acordavam os gentios com os judeus em na persseguiçom dos cristãos" (I. c. 27, 133). Já confessadamente a partir da Glosa, retifica-se também o local onde Paulo falava a gentios e gregos: não foi em Jerusalém, como afirma Lucas, mas sim na Síria e na Cilícia, conforme relata Paulo em Gal 1, 21 e é citado por Bernardo de Brihuega (I, c. 27, 134-135). Neste processo de revisão, o autor aduz a explicação da Glosa para estas discordâncias: "Sam Lucas [que] tanto pôs a estória brevemente que a revolveo". Um tal reconhecimento poderia tê-lo conduzido um pouco longe na crítica dos Atos, uma vez que, justamente neste passo, se refere que Paulo declarara: "E nom me conheciam em nas egrejas de Judea per face, as quaes eram ante a face de Cristo, d'ouvida tam solamente o haviam, porque "O que nos andava perseguindo prega agora a fé que algũas vezes combatia»" (I, c. 27, 135) ${ }^{17}$. Por conseguinte, não poderia ter estado presente na morte de Estêvão, conforme hoje se reconhece (Couto, 2008), mas não é comentado pelo compilador. De resto, a alegada presença naquele episódio potenciava o antagonismo com a conversão.

Desconhece-se qual o método de trabalho de Bernardo de Brihuega, mas, do que observamos relativamente a Paulo, pode inferir-se que se circunscrevia às críticas da Glosa, tomando como verdade mesmo as falsas atribuições, como a errada referência à Carta aos Gálatas (I, c. 27, 133), não ousando avançar

15 Como dissemos, o autor deve ter seguido o comentário da Glossa ordinaria a Act 9, 24, onde se corrige a informação aduzida por Lucas, citando erradamente a epístola aos Gálatas.

16 Cf. PL, 113, col. 449: "Non Judaei, sed cives cum rege suo Aretha, ut ipse scribit ad Galatas. Judaeis enim concordabant Gentiles in persecution Christianorum".

17 A tradução não é muito clara. Cf. Gal 1, 22-23: "eram autem ignotus facie ecclesiis Iudaeae quae erant in Christo tantum autem auditum habebant quoniam qui persequebatur nos aliquando nunc evangelizat fidem quam aliquando expugnabat". 
hipóteses que não estivessem estribadas em auctoritas. Noutros momentos, o recurso à citação das cartas, por vezes em latim e em português ${ }^{18}$, seria uma forma deliberada de corroborar a crítica seguida para que, como diz, não subsistissem quaisquer dúvidas.

A par desta atitude de revisão algo controlada, Bernardo de Brihuega prolonga a ótica harmonizadora que os Atos intentaram. Os passos em que aduz desculpas para a separação havida entre Paulo e Barnabé aparentam ser da sua responsabilidade, numa atitude próxima da tomada no início da Vidas e paixões dos apóstolos, quando o autor busca uma legitimação das sortes que decidem quem haveria de ser o décimo segundo apóstolo, em substituição de Judas (I, c. $2^{19}$ ). No caso vertente, Bernardo de Brihuega relata que Barnabé e Paulo, destinados pelo Espírito Santo à evangelização (Act 13,2,VPA ${ }^{20}$ II, c. 79, 8), levam consigo João Marcos, primo de Barnabé, para Antioquia; quando mais tarde se dirigiram a Panfília, João separa-se deles e regressa a Jerusalém (Act 13,13, VPA II, c. 81, p. 10). As razões que o movem não são explicitadas, nem nos Atos nem nas Vidas, no entanto, mais tarde, quando Barnabé quer a companhia de Marcos, Paulo não consente porque "nom fora com eles em na obra que começarom. E por ende se desacordarom Sam Paulo e Sam Barabas, de guisa que se partio ũu do outro" (II, c. 91, 29). Independentemente de Bernardo de Brihuega ter a perceção da transferência da mais violenta e substancial discussão entre Pedro e Paulo (Gal 2, 11-14) para a dissensão entre Paulo e Barnabé, que se lê Atos (Neves, 2008) talvez na sequência do teor da glosa ${ }^{21}$, afigura-se compelido a legitimar as divergências entre os apóstolos, por forma a anular a dimensão pecaminosa de pecados de língua como "baralha", "contenda” ou "desacordo" (Casagrande e Vecchio, 1987).

\footnotetext{
18 V. por ex., o capítulo 27.
}

19 Cf. I, c. 2, 26-27: "E, sobre aquelo que diz Sam Lucas que deitarom sortes os apóstolos, sabede que diz Sam Jeronimo que nós, por aquelo, nom devemos usar de deitar sortes, u diz (...) «Os privilégios dos poucos nom fazem lei comunal a todos». E, de mais, eles deitaram-nas porque ainda nom lhes fora enviado compridamente o Spiritu Sancto per que se governassem, e governavamse a semilhança das cousas que forom feitas em na Velha Lei, u leemos em muitos logares que forom deitadas as sortes, ca Saul per sorte foi enlejudo por rei. E os apóstolos a esta semelhança as deitarom. E, por todo aquesto, nom as devemos nós a deitar em na nossa lei, mais, se algum for constrenjudo de deitar sortes per força, faça assi como fezerom os apóstolos: rogue primeiro a Deus que faça i o que ele tever por bem".

20 Abreviatura de Vidas e paixões dos apóstolos.

21 Cf. "Non in hoc delinquebant, quia non omis commotio est peccatum, sed irrationabilis, et quae juste non fit" PL 113, col. 458. 
Convoca, então, uns anónimos "sanctos [que] dizem que não podia ser que eles baralhassem, ca tanto queria bem ũu ao outro nem o castigaria que ao outro nom prouguesse e lho non sofresse" (II, c. 91, 30) e repete e adapta a justificação do afastamento entre Paulo e Barnabé e os outros discípulos, que anteriormente havia aduzido nos Atos $(13,2)^{22}$ : "Mas dizem que foe vontade do Espiritu Sancto que teve por bem que se partisse ũu do outro, por tal que andassem per mais terras e per mais logares (...)" (II, c. 91, 30).

Ora, sobre esta zanga Paulo nada diz nas cartas, contrariamente à censura que dirige a Pedro, acusando-o frontalmente de hipocrisia:

cum autem venisset Cephas Antiochiam in faciem ei restiti quia reprehensibilis erat12 14 sed cum vidissem quod non recte ambularent ad veritatem evangelii dixi Cephae coram omnibus si tu cum Iudaeus sis gentiliter et non iudaice vivis quomodo gentes cogis iudaizare. (Gal 2, 11 e 14$)^{23}$

O motivo da discórdia é uma questão fundamental no apostolado de Paulo e prende-se com os limites da "solidariedade de mesa", após a revelação do ressuscitado. Pelo lugar ocupado por Pedro na igreja de Jerusalém, reproduzir nos Atos o teor da altercação havida, seria adensar uma divergência que o autor não quereria fixar, com receio de perturbar a coerência evangélica, a imagem do Cristianismo primitivo e a heroicidade e santidade de Paulo, que surge, nas cartas, como um radical irascível, ainda que em nome de uma liberdade que os Atos não valorizam (Neves, 2011). No entanto, nem os Atos nem as Vidas escamoteiam as divergências havidas entre a igreja de Jerusalém e a de Antioquia, bem visíveis quer quando Paulo e Barnabé vão consultar os Apóstolos e os Velhos da Assembleia de Jerusalém (Act 15, VPA II, cs. 85-86), quer, no final, quando o apóstolo é condenado no Templo (Act 21, 25, VPA II, c. 109).

22 Pedro e Paulo haviam sido destinados à evangelização pelo Espírito Santo. Cf. Act 13,2, VPA II, c. 79,8 .

23 De facto, Lucas situa em Jerusalém a discussão em que Pedro recorda que o Espírito Santo não distingue pagãos de judeus e se pronuncia a favor da salvação pela graça. No entanto, a carta os Gálatas revela-o mais flébil: enquanto Tiago apóstolo não chegou a Antioquia, Pedro comeu sempre com os gentios, mas depois, com receio dos que defendiam ritos como a circuncisão, passou a disfarçar. 
Face a alguns dos pontos em causa na perpetuação da lei de Moisés, a saber, os rituais de circuncisão, o respeito do sábado e os interditos alimentares, a posição de Paulo foi sempre muito clara na condenação dos legalismos exteriores e da sua imposição aos pagano-cristãos, pois o homem é justificado pela graça e não pelas obras. No século xiII, porém, aquela discussão já não se afigura relevante, como poderá deduzir-se de pontuais historicizações nas Vidas e paixões dos apóstolos. Assim, quando Tiago, o responsável pela igreja de Jerusalém, assume uma posição mais conservadora e se pronuncia, por duas vezes, sobre a necessidade de que os pagãos convertidos se abstenham "a contaminationibus simulacrorum et fornicatione et suffocatis et sanguine" (Act 15, 20) ${ }^{24}$, está a ratificar a proibição de comer carne sacrificada aos ídolos. Ora, neste ponto, a tradução portuguesa apenas mantém a anatematização dos ídolos, substituindo a referência alimentar por acrescentos de uma época já distanciada do proselitismo primitivo e mais atenta aos pecados capitais: "luxamento dos idolos e do fornizio e de cobiiça maa e d'avareza, que é servimento dos idolos" (II c. 86, $19^{25}$ ). No entanto, no capítulo sobre a prisão de Paulo em Jerusalém, Tiago renova a sua proscrição nos mesmo termos (Act 21, 25), agora traduzidos de forma mais próxima, ainda que a alteração enumerativa ${ }^{26}$, apesar de aludir ao interdito do sangue, não seja clarificadora: "que se devem guardar dos idolos e do seu sacrificio e do fornizio e do sangue" (II c. 109, 57).

Estas adaptações ou incompreensões mostram um compilador aparentemente indiferente à contestação da teologia assente no Antigo Testamento. De facto, muitos são os passos em que se operou uma adaptação das referências históricas a mundos mais consentâneos com os recetores medievais. É o que ocorre com a pitonisa que Paulo exorcizou e converteu, atraindo a si a perseguição dos patrões por terem deixado de lucrar com o negócio da adivinhação (Act 16, 16-19) ${ }^{27}$. Na tradução portuguesa, o texto fica um tanto impreciso, pois da "manceba" apenas se diz que "havia o mau espiritu e gaanhava per ele a seus senhores todo quanto haviam mester" (II c. 94, 33), não se esclarecendo de que ofício se tratava.

\footnotetext{
24 V. também os mesmos termos em Act 15, 22.

25 V. a tradução igual na p. 20.

26 Cf. Act 21, 25: "(...) ut abstineant se ab idolis immolato et sanguine et suffocato et fornicatione".

27 Cf. 28, 16, 16: "puellam quandam habentem spiritum pythonem obviare nobis quae quaestum magnum praestabat dominis suis divinando".
} 
Já na identificação de "gens" ou "gentilis" com 'gentios' ou 'gentes indiscriminadas' domina a tradução literal por "gentes" e "gentios", respetivamente, neutralizando-se, no primeiro caso, a especificidade sociológica e religiosa ${ }^{28}$. Só muito pontualmente "gentes" é traduzido por "gentios". Talvez pelo contexto de rutura com os judeus que perseguem Paulo e Barnabé, lê-se que os apóstolos decidem voltar "a falar aos gentios", quando na Vulgata se usa "gentes" $(13,46)$. A tradução acertada, embora pouco comum, repete-se em amplificação imputável ao compilador ("E entom tornou-se Sam Paulo contra os gintios") e, por razões coesivas, na tradução do versículo seguinte ("E os gentios, quando ouvirom aquesto", II c. 82, 13). O mesmo nome é ainda usado numa curiosa amplificação sinonímica de "Graecis" em "gentios" e "helenistas"29. De resto, a norma consiste em usar "gentio" só para traduzir "gentilis". De um modo geral, o tradutor ou copista não arrisca a clareza lexical necessária, talvez por alguma distância histórica em relação à realidade conflitiva que judeus e pagãos viveram nos primórdios do Cristianismo e que foi particularmente atuante no percurso de Paulo, precisamente o apóstolo dos gentios.

Finalmente, o aspeto mais evidente na reescrita de Paulo, ou seja, o preenchimento do que o autor considerou serem lacunas daquele percurso do apóstolo. Quando Bernardo de Brihuega, seguindo os Atos, aborda o discurso de Paulo em Atenas e a estátua ao deus desconhecido, sem outra razão que não seja reavivar a memória e sublinhar a coesão interna da obra planeada, amplia o episódio com o contributo do Evangelho de Lucas, a repetição e remissão do que contara "mui compridamente em no Primeiro Livro, (...) da paixom de Jesu Cristo" (cap. 99, p. 41) e um pouco do que retomará "Mais adeante, em no Terceiro Livro", a propósito da Paixão de S. Dinis convertido por Paulo (II, c. 100, 42).

Já a narrativa da vida de Paulo após os dois primeiros anos em Roma fornece um desenlace que os Atos dos apóstolos haviam calado. Demonstrando o comportamento típico destas amplificações que, distintamente do texto sagrado, convivem mal com o vazio, as Vidas e paixões dos apóstolos preenchem o hiato

28 V., a título e exemplo, o cap. 22 que cita Gal 1,16 ("in gentibus") e acrescenta a tradução "antre as gentes" (II c. 138, 115). Em qualquer tradução atual da Bíblia, nestas circunstâncias, usa-se "gentios" ou "pagãos".

29 Cf. I c. 27, 134: "falava com gentios e disputava com helenistas", enquanto na Vulgata se lê apenas "loquebatur quoque et disputabat cum Graecis" (Act 9, 29). A partir daqui, sempre que se cita um texto bíblico, recorre-se à Vulgata, mas sem a mencionar. 
entre a chegada de Paulo à capital do Império e a condenação final. Em termos narrativos, Roma fora primeiro uma meta pessoal a que Bernardo de Brihuega acrescentou um inevitável desígnio divino ${ }^{30}$; posteriormente, a ida à capital do Império é reafirmada em consonância com o sistema jurídico da época e sempre de acordo com um plano providencial ${ }^{31}$ : acusado pelos judeus por dissidências religiosas. Paulo é preso pelas autoridades civis; ora, enquanto cidadão romano sem culpa formada, o réu tinha o direito de apelar para César ${ }^{32}$. Face a esta causalidade, a chegada a Roma não deveria limitar-se ao desfecho de uma viagem atribulada levada a bom termo por intercessão divina, mediada por Paulo. No entanto, nos Atos, o julgamento não é consumado, contrariando a expetativa criada pelas sucessivas instâncias em que o apóstolo fora ouvido antes de se defrontar com o Imperador. Ora é justamente para colmatar esta lacuna que Bernardo de Brihuega se socorre de uma versão tardia dos Acta Petri (180-190), a Passio sanctorum apostolorum Petri et Pauli, do Pseudo-Marcelo ${ }^{33}$, o apócrifo onde a associação da atividade missionária de Pedro e Paulo é mais evidente ${ }^{34}$.

No que a Paulo concerne, o compilador enxerta a nova fonte quando, já em Roma, Paulo discute com os judeus pelos mesmos motivos que ali o tinham conduzido: a obrigatoriedade dos ritos mosaicos. Os judeus repreendem-no por desrespeitar a circuncisão ("ca nom é dereito que tu (...) te faças defendedor daqueles que nom som circuncidados" (II c. 137, 109)) e pedem que interceda junto a Pedro por defender "que nom devem seer guardados os (...) Sabados nem as (...) festas" (ibid.). Paulo apenas responde à última parte, confirmando a

30 Cf. VPA II, c. 105, 49: "Paulo resolveu ir a Jerusalém, passando pela Macedónia e Acaia. "Depois de eu lá ter estado, disse ele, tenho de ver Roma também»" (Act 19, 21) e "(...) pensou Sam Paulo, pelo Spirito Sancto, de passar per Macedonia e de ir a Jerusalém. - Ca, des que i for, - disse el - convem-me de ir a Roma”.

31 Após o julgamento em Jerusalém, "apareceu-lhe Nosso Senhor Jesu Cristo e disse-lhe: Paulo, sei firme, ca, assi como tu testemunhaste de mi em Jerusalém, assi te convem a testemunhar em Roma" (II c. 113, 65). Cf. Act 23, 11.

32 V. a explicação de Pedro Comestor e a fala de Paulo perante o governador Festo (II c. 120, 78).

33 Cf. Lipsius, Ricardus Albertus and Maximillianus Bennet, eds. ACTA Apostolorum Apocrypha Post Constantinum Tischendorf. Lipsiae: Hermann Mendelsohn, 1901; e http://webpages.ursinus. edu/jlionarons/wulfstan/PsMarcellus.html. Uma tradução inglesa pode ler-se em New Testament apocrypha. Vol. II. Writings relating to the apostle; Apocalypses and related subjects. Revised Edition. Edited by Wilhelm Schneemelcher. English translation edited by R. McL. Wilson, Louisville: Westminster /John Knox Press, Cambridge: James Clarkr \& Co Ltd, 2003, 440-444.

34 Segundo Mário Martins, usou muito provavelmente um "Pseudo-Marcelo refundido" (1980: 224). V. o confronto com a edição das Acta Apostolorum Apocrypha (t. 1, Lipsiae, 1891, pp. 119-177), a páginas 218-219. 
necessidade desta prática e nada dizendo sobre a circuncisão (II c. 137, 109-110). No entanto, deve dizer-se que este acrescento acaba por continuar as hesitações perante um Paulo dissidente, intuídas em capítulos anteriores, ao mesmo tempo que transfere para Pedro o que fora uma acusação dirigida a Paulo, em Jerusalém. Se antes percebemos que Bernardo de Brihuega prolonga a atitude de Lucas relativamente à neutralização das divergências entre Paulo, Pedro e Tiago, este passo - independente, é certo, uma vez que deriva de uma outra fonte - reforça em parte essa mesma intenção. Não sendo assim, a cisão de Paulo legitimaria a intenção de o matar, declarada no início do capítulo (II c. 137, 109). A narrativa prossegue sem que a incerteza seja dilucidada. De resto, uns capítulos à frente, o tema da circuncisão é retomado e Paulo regressa ao que parece ter sido a sua posição, ainda que nem sempre isso fique tão claro como nas cartas. Desvalorizando a prática, o apóstolo declara: "Ante que nós tevessemos a fe e a verdade, tevemos a Lei da circoncisom da carne, mais agora, quando entendemos a fe e a lei, doemonos do nosso mal e circuncidámos os corações por fe e por crença” (II c. 140, 126).

No momento da primeira discussão entre Paulo e os judeus, Bernardo de Brihuega interrompera a fonte que estava a seguir para, mais uma vez, retomar o passado de Paulo e a sua conversão (II, c. 137, 110-111) ${ }^{35}$, na sequência do ênfase e concretismo que os Atos lhe haviam concedido ${ }^{36}$. Com efeito, além da narrativa da conversão em que Bernardo de Brihuega seguira o capítulo 9 dos Atos, também recorrera à informação da epístola aos Gálatas para recordar esse momento fulcral da existência do santo ${ }^{37}$. Com tanto realce, afigura-se estranho o silêncio a que as duas obras votaram o arrebatamento de Paulo ao terceiro céu, o traço mais individualizador do seu processo de transformação, contado por ele próprio (2 Cor 12, 1-4). O passo insere-se nas visões do Senhor, mas é reportado a um homem que Paulo diz conhecer. Se a sua omissão corresponde ao receio das tentações de orgulho, a dificuldades hermenêuticas suscitadas por este terceiro céu ou se tem qualquer outro fundamento, será matéria para um paulista

35 A conversão é de novo abordada mais à frente. Cf. VPA II, c. 139, 123, tal como na Passio: "Et Petrus ait: Omnia quaecumque locutus est Paulus uera sunt. Nam multi anni sunt, per quos accepi litteras ab episcopis nostris, qui sunt in uniuerso orbe Romano, et paene omnium ciuitatum episcopi scripserunt mihi de factis et dictis eius. Nam cum persecutor esset legis Christi, nox eum de caelo uocauit et docuit ueritatem, quia non erat per inuidiam. inimicus fidei nostrae sed per ignorantiam" http://webpages.ursinus.edu/jlionarons/wulfstan/PsMarcellus.html

\footnotetext{
36 V. VPA I, c. 22 (Act 9, 3-4), II, c. 111 (Act 21, 40) e II, c. 122 (Act 26).

37 V. VPA I, c. 27 , Gal 1, 15-16, II, c. 88, Gal 1, 15-2, 2.
} 
dilucidar, mas surpreende que a ideia de um rapto místico não tenha seduzido as mentalidades fantasiosas dos dois autores.

Quando o compilador retoma a Passio, esquece o pomo da discórdia antes mencionado $^{38}$, e, enquanto o texto latino passa de imediato à conversão das mulheres de Nero e do governador, o português acrescenta a responsabilidade dos "senhores das sinagogas e os bispos dos gintios" (II c. 139, p. 113) no conluio com Simão Mago e com Nero ${ }^{39}$. Só depois destas variações - cuja origem se afigura mais imputável a uma eventual refundição da Passio do que à ação do compilador, que não se tem revelado grandemente criativo ou interventivo -, regressa de novo ao texto latino: Simão e suas disputas com Pedro e também com Paulo, embora em segundo plano; a vinda destes perante o imperador que tentam, em vão, doutrinar; a prova da ressurreição do mago, sua morte; e consequente condenação, martírio e enterro dos santos (II cs. 138 a 146).

De acordo com as narrativas das Vidas e paixões dos apóstolos e da Passio, que aquelas agora seguem na generalidade, a causa imediata da morte de Paulo é apresentada não como uma consequência das clivagens doutrinais denunciadas em Jerusalém, mas do envolvimento dos apóstolos na derrota de Simão e do desprezo que manifestaram pelos seus encantamentos e pelas crenças de Nero. Na prova da ressurreição, Simão prometera lançar-se de uma torre, sendo sustido por seus anjos, contudo Pedro ordena-lhes que o deixem cair (II c. 140, 128-131). Como reação, Nero determina que Pedro e Paulo "moiram malamente", mas é aconselhado a distinguir as penas respetivas, pois "Paulo nom ha i tam gram culpa como Pedro, que fez morrer Simhom Mago” (II c. 141, 132). Mais tarde também se diferencia a categoria social: Paulo, "porque era fidalgo, quis [Nero] que fosse scabeçado porque é mais honrada morte" (II c. 145, 146). E a narrativa termina

38 De facto, a dúvida formulada pelos judeus não chega a esclarecer-se nem nas Vidas e paixões dos apóstolos (cap. 138, 112), nem mesmo na Passio. Nas primeiras, transita-se para uma pregação de Pedro, assente na leitura tipológica do que "Espirito Sancto prometeo a David" (cap. 138, 112); no apócrifo latino, à discussão entre os judeus e Paulo segue-se o encontro entre Pedro e Paulo e a disputa entre judeus e gentios que, em Bernardo de Brihuega, fora narrada no capítulo anterior (cap. 136). Perante estas alterações, será necessário proceder a um confronto sistemático entre as fontes usadas e a lição de Bernardo de Brihuega, para melhor compreender se as modificações introduzidas são da sua responsabilidade ou se são imputáveis às lições seguidas, como sugeriu M. Martins (1980), a propósito da Passio sanctorum apostolorum Petri et Pauli.

39 Cf. II c. 138, p. 113: "poserom com ũu encantador que havia i com Nero, o emperador, que parasse mentes em no que aqueles homẽes andavam fazendo". 
com o enterro dos dois evangelizadores realizado por "ũus homẽes sanctos" vindos de Jerusalém com esse propósito (II c. 140, 127).

Este desenlace aparatoso, sem dúvida ao gosto dos recetores contemporâneos, é de certa forma emblemático da novidade que a ressurreição constituíra no Cristianismo primitivo, suscitando émulos anti-crísticos. Apesar de entrecortada por capítulos consagrados a outros apóstolos, a narrativa de Bernardo de Brihuega sobre Paulo captou o essencial da sua pregação, centrando-se na ressurreição dos mortos e na discussão dos legalismos mosaicos, as diferenças essenciais formais e substanciais - que separavam o Cristianismo do Judaísmo, mas também na memória da conversão. Neste aspeto, como se verá, as Vidas e paixões dos apóstolos oferecem, quer pelo confronto com as Cartas, quer pelo desfecho acrescentado, a versão mais completa da vida de Paulo e a mais fiel à dinâmica apostólica do pregador. Na conjugação das três fontes principais, Atos, Cartas e Passio, o compilador revela um à vontade complacente quer com as imprecisões do texto matriz que refunde, quer com a imaginação delirante do Pseudo-Marcelo. A ambivalência do resultado deve-se justamente à natureza canónica dos Atos e apócrifa da Passio, e à facilidade com que Bernardo de Brihuega os coloca em diálogo igual com os testemunhos de Paulo ou com as correções críticas que com tanta probidade cita, se calhar muito sintomaticamente, apenas a propósito dos Atos. O sentido, a defesa da doutrina dominavam as preocupações. O romanesco e o maravilhoso eram ornati instrumentalizados.

Excetuando o desenlace, a figuração de Paulo nas Vidas não dista muito da conformação do santo nos Atos dos apóstolos. Contudo, o texto de Bernardo de Brihuega, nas suas hesitações e justificações, no início do acrescento apócrifo ${ }^{40}$, de alguma forma sinaliza e ilumina pontos sensíveis do relacionamento de Paulo com apóstolos e discípulos e do que a personagem poderá ter, de facto, significado num contexto de grande diversidade religiosa, como melhor se percebe pelas cartas. De facto, o compilador de Afonso X não consegue iludir algum desconforto perante o que, aparentemente na senda dos comentaristas, poderia configurar uma imagem menos abonatória dos apóstolos. Em relação a Paulo, esse mal-estar é visível tanto na justificação/interpretação que se acrescenta, como na argumentação arrastada que, podendo explicar-se por dificuldades

40 V. supra a referência à disputa entre judeus e Paulo e as acusações a Pedro. 
expositivas, também poderá decorrer de algum pudor na questionação do texto canónico, ainda que socorrendo-se de outro com o mesmo estatuto, como são as cartas, ou de auctoritas inquestionáveis. É possível que alguma falta de assertividade no confronto textual se prenda com o facto de a escrita em vulgar envolver uma responsabilidade acrescida, na medida em que, ainda que de circulação restrita, o texto era, em potência, compreensível por todos os falantes.

De certa forma, o que fica menos claro, tanto nos capítulos que reescrevem os Atos como nos que introduzem a Passio, tem a ver com a discussão dos formalismos mosaicos e com as causas da condenação de Paulo. Pouco claras no texto dos Atos, acabam por não ter um desenlace coerente e consequente nas Vidas, porque, se bem que, no momento em que se insere o apócrifo, se comece por abordar conflitos doutrinais, o dissídio rapidamente se desvia para as disputas com Simão Mago, transformando-se um conflito inicial entre judeus e cristãos num mais radical antagonismo entre cristãos e pagãos. O fim que Bernardo de Brihuega, na sequência do Pseudo-Marcelo, desenha para Paulo, confrontado com as propostas diferentes de ficções hagiográficas como as do Flos sanctorum, atesta bem a necessidade de encerrar um capítulo nebuloso da história do Cristianismo, ainda hoje em discussão. 


\section{BIBLIOGRAFIA}

CASAGRANDE, Carla / VECCHIO, Silvana (1987). I peccati della lingua : disciplina ed etica della parola nella cultura medievale. Roma : Istituto della Enciclopedia Italiana.

CEPEDA, I. (1975). "Um fragmento inédito das Vidas e paixões dos apóstolos". Boletim de Filologia. 24: 295-304.

(1993). "Autos dos Apóstolos". G. Tavani, G. Lanciani (orgs.). Dicionário da Literatura Medieval Galega e Portuguesa. Lisboa: Caminho. 75-76.

, (ed.) (1982-1989). Vidas e paixões dos apóstolos. 2 vols. Lisboa: Instituto Nacional de Investigação Científica.

COUTO, D. António (2008). "Paulo, modelo de evangelizador", Theologica. II S. vol. XLIII/2: 317-373.

Glossa ordinaria, in PL, 113-114.

LIPSIUS, Ricardus Albertus and BENNET, Maximillianus (eds.) (1901). Acta Apostolorum Apocrypha Post Constantinum Tischendorf. Lipsiae: Hermann Mendelsohne http:// webpages.ursinus.edu/jlionarons/wulfstan/PsMarcellus.html. Acedido em Janeiro de 2009.

MARTINS, M. (1949). "Vidas e paixões dos apóstolos". Brotéria. 49: 521-528.

(1963). "Bernardo de Brihuega, compilador dos Autos dos Apóstolos". Boletim de Filologia. 21: 69-86.

(1980). "O romance do Pseudo-Marcelo". Estudos de Cultura Medieval. II. Lisboa: Brotéria. 217-228.

NEVES, Joaquim Carreira das (2008). O Que é a Bíblia. Lisboa: Casa das Letras. (2011) São Paulo. Dois mil anos depois. Lisboa: Editorial Presença.

SCHNEEMELCHER, Wilhelm (2003). New Testament apocrypha. Vol. II. Writings relating to the apostle; Apocalypses and related subjects. Revised Edition. English translation edited by R. McL. Wilson, Louisville: Westminster/John Knox Press, Cambridge: James Clarkr \& Co Ltd.

VAUCHEZ, André et al. (2000). Encyclopedia of the Middle Ages. Cambridge: James Clarke \& Co - Chicago: Fitzroy Dearborn Publishers. 